\title{
História, movimento e equilíbrio nas "Reflexões sobre a vaidade dos homens", de Matias Aires
}

Mannuella Luz de Oliveira Valinhas Universidade Estadual de Minas Gerais

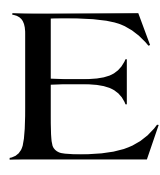

m 1752 são publicadas, em Portugal, as "Reflexões Sobre a Vaidade dos Homens ou Discursos Morais sobre os Efeitos da Vaidade Oferecidos a El-rei Nosso Senhor D. José I", de Matias Aires Ramos da Silva de Eça. Obra de caráter filosófico, cujo principal objetivo era traçar um perfil do homem moderno e da natureza de suas ações - ou seja, definir qual a finalidade última que fundamenta o comportamento do homem em sociedade. Matias Aires encontra essa finalidade no desejo de reconhecimento inerente ao homem. Assim, o motor das açóes humanas será esse desejo de reconhecimento, uma concupiscência do espírito, a vaidade.

Matias Aires, ao produzir um tratado sobre a vaidade, acaba por elaborar um tratado sobre a própria natureza humana. Mesmo não formalizando um conceito único daquilo que seja a vaidade, ele a define como uma "paixão da alma”. ${ }^{1}$ Contudo, seu objetivo maior é demonstrar, através

1 "A imaginação desperta e dá movimento à vaidade; por isso esta não é paixão do corpo, mas da alma; não é vício da vontade, pois depende do discurso". AIRES, Matias. Reflexões sobre a vaidade dos homens. São Paulo, Editora Martins, 1942. Número 14. (como as "Reflexões" são separadas e numeradas, opta-se, aqui, por citar o número da "Reflexão", o que facilita a consulta a outras edições da obra.) Muitos leitores aproximam a vaidade de Matias Aires ao conceito de amour-propre (La Rochefoucauld). No texto Humores e Simetrias das Máximas, Pécora discorre sobre o sentido específico adotado por La Rochefoucauld 
da exposição de toda a sorte de ações humanas, que certo tipo de vaidade, de desejo de reconhecimento, sempre estará presente nelas - ou seja, existe alguma espécie de vaidade em todas as açóes executadas pelos homens.

Embora caracterizada como um vício do espirito, a vaidade não se resume a ser somente boa ou somente má: ela nasce com o homem - ou melhor, a mesma natureza que criou o homem cria a vaidade - e serve tanto à separação individual ${ }^{2}$ quanto à fundação da sociedade. A vaidade, como elemento fundador das relaçóes entre os homens e, portanto, da sociedade, também é responsável pelas hierarquias estabelecidas socialmente: sem a necessidade de reconhecimento ou aprovação por parte dos outros homens, não seriam formados os elos sociais:

A diferença e desigualdade entre os homens é uma das partes, em que se estabelece a sociedade, por isso esta se funda em princípios de vaidade; porque só a vaidade sabe corporificar idéias e fazer diferente, desigual, o que é composto por um mesmo modo e organizado de uma mesma forma. Os homens mais vaidosos são os mais próprios para a sociedade: aqueles que por temperamento, por razão, ou por virtude se fazem menos sensíveis aos impulsos da vaidade, são os que pela sua parte contribuem menos na comunicação dos homens: ocupados em uma vida mole, isenta e sem ação, só busca no descanso a fortuna sólida, e desprezam as imagens de que se compóe a vaidade da vida civil. ${ }^{3}$

dessa noção de amor-próprio. PÉCORA, Alcir. Máquina de gêneros: novamente descoberta e aplicada a Castiglione, Della Casa, Nóbrega, Camões, Vieira, La Rochefoucaud, Gonzaga, Silva Alvarenga e Bocage. São Paulo; EDUSP, 2001. Ver também: COELHO, Jacinto do Prado. Reflexōes sobre as reflexōes. In: AIRES, Matias. Reflexóes sobre a vaidade dos homens e Carta sobre a fortuna. Lisboa; Imprensa Nacional - Casa da Moeda, 1980. Penso que a vaidade é sempre relacional para Matias Aires e não se esgota na idéia de amor próprio. ${ }^{2}$ A vaidade tem seu caráter pernicioso acentuado quando seu efeito é um individualismo exacerbado, contrário à coesão social. Sobre isso ver: MESQUITA, 1997.

${ }^{3}$ AIRES, 1942, n. 24. 
"A vaidade introduz a virtude no mundo através da conversão em socialmente útil o que seria naturalmente mau". ${ }^{4}$ Desse modo, os qualificativos de "bom" ou "mau" para a vaidade são relativos conforme se observe de uma perspectiva individual ou social - a perspectiva social garante o qualificativo positivo - a vaidade engendra virtudes; e a individual, o negativo - a vaidade exagerada separa os homens e pode romper os laços sociais. O vício da vaidade se tornando capaz de gerar virtudes sociais (o próprio vício da vaidade é uma virtude social) faz com que a vaidade seja responsável pela geração de uma segunda natureza bumana: a natureza social. 5 Ao lado da natureza "natural" do homem, a vaidade introduz a natureza social, cabendo a ela a própria tarefa de humanização do homem de acordo com a sua natureza (sua natureza social). De acordo com a análise de Mesquita, ${ }^{6}$ a vaidade se torna, assim, responsável não apenas pela "coesão social”, mas pela própria humanização individual.

Partindo de tal caracterização da sociedade e do homem cabe, agora, apresentar outra idéia fundamental para a compreensão da obra de Matias Aires: a noção de que as coisas vivem em perpétuo movimento, movimento este que se constitui em uma transformação perpétua. Nesse movimento podem surgir efeitos contrários às suas causas, o que o impede que ele aconteça em uma única direção; esse caráter do movimento garante, ainda, que sua quantidade seja constante, devido à existência do equilíbrio entre pólos opostos. ${ }^{7} \mathrm{O}$ equilíbrio em perpétuo movimento garante a vida. Dessa forma, um vício pode engendrar uma virtude (como acontece com a

${ }^{4}$ MESQUITA, 1997, p. 79.

${ }^{5}$ Não é a razão colocada como guia final, ou organizadora da sociedade; ela, como uma função do intelecto, é menos forte do que uma paixão do espírito, como a vaidade. E nesse caso, mais que uma paixão, uma componente da própria natureza humana.

${ }^{6}$ MESQUITA, 1997.

${ }^{7}$ Essa idéia está sempre associada à máxima de La Rochefoucauld que diz: Les vices entrent dans la composition des vertus comme les poisons entrent dans la composition des remèdes. Citado por: PÉCORA, 2001. 
vaidade $^{8}$ ), e tudo o que tem vida existe em movimento contínuo. ${ }^{9}$ Assim é com a natureza, que a todo tempo está se transformando.

Ao elaborar um tratado sobre a moral, Matias Aires não descarta as discussōes sobre o mundo natural. O estudo da moral, para os pensadores do século XVIII, não estava desvinculado do estudo sobre a natureza, tanto a natureza exterior ao homem, quanto a própria natureza do homem. ${ }^{10} \mathrm{O}$ êxito da física newtoniana e do paradigma mecanicista a partir de finais do século XVII tem uma grande influência sobre o pensamento de Matias Aires. A explicação da totalidade física tornara-se mecanicista, e a natureza se torna capaz de representar a onipotência divina e de sua Criação, a partir da equivalência entre os desígnios divinos e as leis naturais. ${ }^{11}$ Para Matias Aires, a Natureza é a manifestação plena da Providência: é possível observar as transformações naturais como manifestações do primeiro movimento, dado por Deus para que a vida pudesse existir. Assim, na sua criação, o homem tem o movimento inicial, continuando em movimento através da alma; mas sua existência física está sujeita às leis da natureza, leis de perpétuo movimento, como as outras criações divinas. $\mathrm{O}$ sopro divino que anima o corpo humano está na alma, e o que anima a natureza está nos fenômenos naturais. O corpo humano faz parte dessa mesma natureza, criada por Deus (a origem divina do Homem e da Natureza não é questionada), mas com uma existência "profana". Deus é o criador do movimento e sua quantidade

8 "Mas se é certo, que a vaidade é vício, parece difícil haver virtude que proceda dele; porém não é difícil, quando ponderarmos, que há efeitos contrários às suas causas.” AIRES, 1942.

${ }^{9}$ Como a vaidade funda a sociedade através de um princípio individualizante e esse mesmo princípio se torna o fator maior de sociabilidade, ou melhor, de sociabilidade possível.

${ }^{10}$ Sobre isso ver: HAZARD, 1989. E também: MARGUTTI PINTO, 2003, p. 253-278.

${ }^{11}$ Ver: HAZARD, 1989. O grande êxito se dá quando a física newtoniana faz uso empírico da matemática. Isso leva, ainda, ao enobrecimento da História Natural. Ver ainda: CUNHA, 2001. 
é constante; ele não continua sendo a causa particular dos fenômenos que, a partir do primeiro movimento, desdobram-se regularmente:

A vida consiste no movimento: quem primeiro o causa é que se diz ser o princípio dele; mas não se segue daqui, que a causa que depois se move fique com alguma porção do princípio que a moveu. ${ }^{12}$

O movimento regular é a vida, e a ausência de movimento é uma característica típica da morte, ou das coisas sem vida. Este movimento, entretanto, é ordenado, regular, incessante, e não se trata, pois, de um movimento anárquico; quando se profana o movimento (uma convulsão é a profanação do movimento corporal, por exemplo) não é possível o entendimento do mundo. $\mathrm{O}$ movimento que dá vida ao homem, se tem origem no Supremo Artífice, tem seu desenvolvimento autonomizado, através do movimento sanguíneo. O sangue é o elemento vital que, em movimento constante dentro dos corpos animais, lhes garante vida. "O sangue é uma entidade material, sujeita a todas as leis da hidrostática e do equilíbrio, e que forma um líquido espirituoso, vital, universal, e igual em tudo quanto respira e é sensitivo"13 (grifos meus). Nesse sentido, para Matias Aires, não há diferença alguma entre o sangue humano e o dos outros animais; assim, não há distinção entre o corpo humano e os outros corpos naturais. Do ponto de vista físico, o corpo humano é figura e movimento, como qualquer outro corpo. ${ }^{14}$ Aquilo que diferencia o homem dos outros animais é a vida em sociedade, ou seja, sua segunda natureza, e a capacidade de conservação da mesma - o corpo social também tem vida e, portanto, movimento, como o corpo individual e a natureza. Pelo caráter de dupla

12 AIRES, 1942.

${ }^{13}$ AIRES, 1942.

14 "O mesmo modo, a mesma arte, os mesmos ingredientes de que a natureza serve para fazer o sangue de um leão, de um elefante ou de uma águia, são os mesmos de que se serve também para formar o sangue de uma pomba rústica, ou de um cordeiro manso; as produções são diversas, a fábrica é a mesma; não há diferença nos princípios, nas figuras sim”. AIRES, 1942. 
natureza do homem (a natureza "natural", compartilhada com os outros animais, e a natureza "social" - a própria especificidade do homem), a sociedade está sujeita às transformaçôes do movimento assim como o homem e a natureza. Na natureza, esse movimento sempre inicia um novo ciclo, e na sociedade, esse novo ciclo pode ser a transformação dos fundamentos da sociedade, dos valores.

Nas sociedades, o mal é mais comunicável; a perdição, mais natural; o que é bom, mais depressa tende a perder-se que a melhorar-se; os frutos da terra quando chegam ao estado de madureza, nem persistem nêle, nem retrocedem para o estado de verdura; antes caminham até que totalmente se arruinem; por isso o último grau de perfeição costuma ser o primeiro na ordem da corrupção. Naquilo que a Providência não predefiniu um ser permanente e inalterável, a natureza não cessa de mover-se enquanto não desfaz, enquanto não corrompe, enquanto não acaba. ${ }^{15}$

Os valores sociais estão, pois, sujeitos ao tempo, à decadência. As sociedades morrem, e os valores, quando fundados sobre coisas vãs, acabam junto com elas. O tempo age, então, como palco para o movimento e a mudança na sociedade. Da mesma forma como atua no corpo físico, levando o homem à morte, à aniquilação do corpo natural, ${ }^{16}$ o tempo age nas sociedades: o mesmo movimento que é responsável por sua existência e duração é responsável por sua aniquilação. O eterno movimento da "fábrica do universo" 17 acaba por apagar os traços de pessoas e sociedades do passado. A constatação disso faz com que o homem chegue ao ápice da vaidade: o desejo de ser perpetuado através da memória. Tal desejo pode ser tanto individual quanto social - a sociedade deseja ser lembrada por suas conquistas. A vaidade de ser lembrado faz com que os homens tenham

\footnotetext{
15 AIRES, 1942.

${ }^{16} \mathrm{O}$ equilíbrio que garante a conservação da espécie humana está na reprodução, mas isso apenas reproduz o homem natural.
}

${ }^{17}$ MESQUITA, 1997. 
atitudes heróicas, escrevam livros ou tentem, ainda, se perpetuar em algo material (de acordo com o autor a última vaidade é a fabricação de túmulos diferenciados). Dessa forma, o homem teria a ilusão de que a morte não o aniquilaria, conquanto vivesse através da memória dos outros homens. Mas, se alguns atos podem fazer com que a lembrança de um homem dure ainda depois de sua morte, tal lembrança fatalmente se extinguirá; pode durar mais no tempo, mas fatalmente estará também sujeita à aniquilação.

Acabam-se os heróis, e também acabam as memórias das suas ações; aniquilam-se os bronzes, em que se gravam os combates; corrompemse os mármores, em que se esculpem os triunfos; e a-pesar-dos milagres da estampa, também se desvanecem as cadências da prosa, em que se descrevem as empresas e se dissipam as harmonias do verso, em que se depositam as vitórias: tudo cede à voracidade cruel do tempo. Acabam-se as tradiçôes muito antes que acabe o mundo; porque a ordem dos sucessos não se inclue na fábrica do Universo; é cousa exterior, e indiferente. Os monumentos, que fazem da história a melhor parte, e a mais visível, não só se estragam, mas desaparecem, e de tal sorte, que nem vestígios deixam por onde ao menos lhes recordemos as ruínas. ${ }^{18}$

O fato de a história ser escrita pelos homens, pelos historiadores, faz com que ela tenha a incompletude característica daquilo que é criado pelo homem. Mais que isso, a narrativa histórica não consegue captar a essência das coisas - tudo o que os homens podem conhecer são os efeitos das coisas, não suas causas - além de a própria escrita da história estar submetida à vaidade, à índole e às inclinações de quem a escreve. Para Matias Aires, a história dos historiadores não trata da "verdade", pois dependeria de uma visão completa dos fatos e de uma isenção do historiador para ser verdadeira. Como isso não é possível, o historiador se torna refém da vaidade de saber fatos, e de escrever sobre si mesmo - sobre sua sabedoria:

18 AIRES, 1942. 
Mas, de quantas ações fará menção a história que jamais se viram? De quantos sucessos que nunca foram? De quantos combates, que nunca se deram? De quantas vitórias, que nunca alcançaram? E de quantos nomes, que nunca houveram? Não é fácil que pelas narrações da história se possa descobrir a verdade dos sucessos; ela comumente se escreve, depois de terem passado alguns, ou muito séculos, de que se segue a que mesma antiguidade é uma nuvem escura e impenetrável, donde a verdade se perde e esconde. Se a história se escreveu ainda em vida dos heróis, o temor, a inveja, a lisonja bastam para corromper, diminuir, ou acrescentar os fatos sucedidos: por isso já se disse que para ser um bom historiador, é necessário não ser de nenhuma religião, de nenhum país, de nenhum partido, de nenhuma profissão; e mais que tudo, se se pudesse, não ser homem. E, com efeito, se alguém se persuade que há de saber a verdade dos sucessos pela lição da história, enganase; quando muito, o que há de saber é a história do que os autores escreveram, e não a verdade daquilo que escreveram. ${ }^{19}$

Matias Aires comprova sua tese "empiricamente", a partir das observações das obras de historiadores que não concordam entre si sobre a veracidade dos fatos narrados - grave crítica, uma vez que a "aporia" da história, sua especificidade narrativa, seria exatamente sua pretensão de verdade em relação aos acontecimentos narrados ${ }^{20}$ - e ainda verifica que as inclinaçóes pessoais dos historiadores interferem na sua narrativa: um jurista tende a privilegiar os temas jurídicos como principais desencadeadores dos eventos, enquanto um político tenderia a discutir idéias políticas, por exemplo.

Não há, pois certeza alguma em nada. A história profana - porque esta é somente a de que falamos - parece que não foi feita para instruir, senão para enganar. Os autores não se contentaram com enredar

${ }^{19}$ AIRES, 1942. E também: "O discorrer com liberdade supõe uma exclusão de todas as paixões; que os homens podem isentar de algumas, pode ser, mas que de todas fique isento ao mesmo tempo, é mui difícil.”

${ }^{20}$ Sobre isso ver COSTA LIMA, 2006. 
o mundo enquanto vivos: quiseram ter o maligno divertimento de deixar na história uma ocupação de estudar enganos: nem todos fizeram por malícia, mas por simplicidade. ${ }^{21}$

Se não pode haver certeza nas narrativas contadas pelos historiadores, a história não deixa de ter uma função: a de ser a base da diferenciação dos homens na sociedade, por meio da legitimação da nobreza hereditária. Esta instituição - a nobreza - cria a desigualdade na sociedade de maneira artificial, pois Deus criou todos os homens iguais, a partir da mesma matéria. Matias Aires analisa o argumento de a nobreza ser transmitida através do sangue e desmente a tese de uma nobreza "natural". A diversidade fundada na antiguidade da linhagem é, para Matias Aires, algo introduzido na sociedade por vaidade humana e se perpetua por meio da história. Mas, se a nobreza foi criada sobre alicerces vãos, ainda serviu para criar hierarquias sociais. Com o tempo, o estatuto nobiliárquico corrompeu-se e é o principal fator de decadência da sociedade analisada por Matias Aires. A valorização da "antiguidade" das coisas (entre elas a das famílias) é algo essencialmente antinatural para o autor, pois significa valorizar o que não mais existe.

A escrita da história, feita pelos homens, tal como entendida por Matias Aires, é uma construção que não remete à verdade dos fatos, mas ao posicionamento dos historiadores ("Os historiadores no que mais se esforçam é em pintar cada um a si, e introduzirem no que escrevem as suas profissóes e inclinaçóes"); $;^{22}$ historiadores esses que servem aos propósitos da nobreza de manutenção artificial das distinções. As narrativas históricas estão, elas também, sujeitas ao tempo e à decadência - são produzidas por homens, e não escapam do movimento. Os registros históricos, sejam eles as narrativas elaboradas pelos historiadores ou documentos e vestígios de períodos passados, não são capazes de sobreviver ao movimento ininterrupto do universo. Uma sociedade que tenha como princípio a legitimação de desigualdades sociais fundamentadas pela história não tem alicerces

\footnotetext{
${ }^{21}$ AIRES, 1942.

${ }^{22}$ AIRES, 1942.
} 
genuínos. Para Matias Aires, esse é o fundamento de uma sociedade decadente.

O livro foi lançado em 1752, período de desaparecimento de uma cosmovisão, que cedia lugar a outra. ${ }^{23} \mathrm{Uma}$ das esferas de pensamento que têm seu arcabouço transformado éa idéia de História e de sua escrita. Neste período, vão se delineando os contornos de uma disciplina histórica, articulada a um tempo histórico específico, que constitui um domínio outro dentro das belas-letras, ou da literatura. ${ }^{24}$

Matias Aires separa, radicalmente, a História Humana da História Providencialista; ou melhor, separa a "escrita da história" (o relato feito pelos homens dos eventos sucedidos) da História (história crua). ${ }^{25} \mathrm{O}$ homem participa da História Divina, Providencial, por ser Criado, e por se integrar à ordem da Natureza individualmente, uma vez que tem um corpo físico, à semelhança dos animais. A sociedade, que como uma segunda natureza garante a humanização do homem, também obedece às regras estabelecidas pela Providência para ter vida e obedece, portanto, a regra de permanecer em movimento equilibrado. Assim como o homem, a sociedade tem, pois, uma relação de semelhança de funcionamento com a natureza, como então terá, como o homem, uma infância, um desenvolvimento, uma maturidade e uma morte. ${ }^{26} \mathrm{O}$ relato dessa passagem no tempo e dos eventos sucedidos durante essa passagem é o que Matias Aires chama de História Profana; e o que nós chamamos de Escrita da História. De acordo com João Adolfo Hansen, dentre as várias características e especificidades da forma mentis luso-brasileira dos séculos XVI ao XVIII, a principal seria "o modo qualitativo de conceber a temporalidade como emanação ou

23 "Entre o século XVI e o final do XVIII toda uma cosmovisão se transforma e uma outra lentamente reponta" COSTA LIMA, 2006, p. 115.

${ }^{24}$ Termo que ainda não detinha o caráter de "criação", e envolvia as produções escritas do período, que eram divididas de acordo com outras regras. COSTA LIMA, 2003, HANSEN, 2006.

${ }^{25}$ COSTA LIMA, 2006.

${ }^{26}$ A sociedade era vista como um corpo místico nesse período. HANSEN, s/d. 
figura de Deus que inclui a história como projeto providencialista”. ${ }^{27} \mathrm{Ou}$ ainda, na análise, elaborada por Koselleck, da noção de história antes do último terço do século XVIII: "La histoire misma procede de Dios y no es outra cosa que el ordo temporum que fija de antemano todos los acontecimientos, y según el quedariam articulados". ${ }^{28}$ A escrita da história, para Matias Aires, não corresponde, ou melhor, não alcança a verdadeira essência da História Providencialista. Assim como somente são conhecidos os efeitos das causas naturais, só conhecemos parcialmente a história, já que, escrita por homens, ela padece de graves defeitos.

Um dos defeitos mais graves da narrativa histórica é a falsidade intrínseca a ela: uma vez que o historiador é homem e, portanto, vaidoso, "o desejo de contar cousas admiráveis e a vaidade que o historiador tem de manifestar que as sabe, é o que fez sempre inventar e escrever sucessos fabulosos". ${ }^{29}$ Nesse sentido, não é que a História seja essencialmente ruim; antes, a impossibilidade de o historiador realizar uma narrativa verdadeira inviabiliza a legitimidade da história do homem como conhecimento da verdade daquilo que ocorreu. O caráter de falso, ou de artificial, de outros tipos de práticas escritas não é critério para tirar a legitimidade dessas outras práticas, uma vez que elas não possuem como critério de validação a verdade. Assim, as "Letras" são criticadas por outros defeitos, ${ }^{30}$ e não por sua adequação à realidade do fato ocorrido. Essa falsidade da história decorre, sobretudo, de duas características do historiador: a vaidade própria da natureza humana (que faz com que o autor "invente" situações para tornar o seu texto mais atraente), e a inexistência de um historiador isento de inclinações pessoais e profissionais. Matias Aires não desvincula a História da Teologia; ele postula que não há uma identidade entre a história escrita pelos homens e a História

${ }^{27}$ HANSEN, s/d.

${ }^{28}$ KOSELLECK, 1993, p. 127.

${ }^{29}$ AIRES, 1942.

30 "A vaidade das letras é maior que a vaidade das armas; estas sim têm ocasião de maior pompa, de maior grandeza e de maior admiração; mas tudo nas armas é semelhante ao raio, cuja luz e estrépito se extingue num instante.” AIRES, 1942. 
Providencialista. Nesse sentido, a história escrita pelos homens deve ser julgada por aquilo que se tornaria característica da historiografia moderna, "que considera o relato historiográfico tendo como guia seu referente, i. e., o contexto de que o relato tratará." 31

Outra característica da história, para Matias Aires, é o seu caráter fragmentário:

A vaidade nos ensina, que as açōes heróicas se fazem imortais por meio das narraçôes da história; porém mal pode caber na lembrança dos homens todos os grandes sucessos, de que se compóe a variedade do mundo: ainda o mesmo pensamento tem limite, por mais que nos pareça imensa sua esfera. Não há história, que verdadeiramente seja universal: quantos Aquiles terão havido, cujas notícias se acabaram, só porque não tiveram Homeros, que as fizesse durar um certo tempo, e isto por meio do encanto de um poema ilustre? Quantos Enéas sem Virgílios? Quantos Alexandres sem Quinto Curcios? Na infância do mundo começaram logo a haver combates, por isso as vitórias sempre foram de todas as idades; porém esses mesmos combates se desfaziam uns a outros; porque a fortuna do vencer sempre foi vária e inconstante. As notícias das vitórias também se vinham a extinguir umas pelas outras. Se quisermos remontar ao tempo que passou, a poucos passos havemos de encontrar a fábula, coberta de um véu escuro, e impenetrável: tudo quanto aquêle tempo encerra nos é desconhecido totalmente. ${ }^{32}$

Matias Aires se situa antes da criação, ou do surgimento, da noção de uma História que articula todas as histórias num fio condutor comum, o conceito de "Historia Universal": de acordo com Koselleck, ${ }^{33}$ até o século

${ }^{31}$ COSTA LIMA, 2006, p. 118. Não estamos tentando, contudo, tecer consideraçôes que levem à conclusão de que Matias Aires era um homem à frente do seu tempo, mas que a delimitação daquilo que é próprio da historiografia está sendo discutida no seu texto, mesmo que tangencialmente. 32 AIRES, 1942.

${ }^{33}$ KOSELLECK, 1993. 
XVIII, falta um conceito comum que conjugue os eventos históricos num sentido único. Nesse sentido, não existe um "procedimento" que articule os eventos num fio condutor de acontecimentos puramente humanos. ${ }^{34}$ Ou ainda: "a descoberta de um genuíno tempo histórico, no conceito de história, coincide com a experiência dos tempos modernos". ${ }^{35}$ Articulando essa passagem à idéia de Gumbrecht de que a modernidade acontece por meio de ondas sucessivas de modernização, e que a primeira dessas ondas compreende o período que vai desde a descoberta do Novo Mundo até o último terço do século XVIII, encontramos nosso objeto (o arcabouço teórico desenvolvido por Matias Aires) situado, então, nessa primeira onda de modernização, que tem, como característica fundamental, ainda de acordo com Gumbrecht, a imersão do sujeito no próprio mundo referenciado por seu discurso. ${ }^{36}$ Matias Aires dialoga com essas concepçôes de mundo, e elabora uma concepção de História que separa a escrita da história da história crua, de uma forma que não há possibilidade de uma analogia verdadeira entre as duas. A narrativa da história, por ser um discurso sobre o mundo (uma representação), é contaminada pelo homem:

O nosso engenho todo se esforça em pôr as cousas em uma perspectiva tal, que vistas de um certo modo, fiquem parecendo o que nós queremos que elas sejam, e não o que elas são. $\mathrm{O}$ discurso é como um instrumento lisonjeiro, por meio do qual vemos as cousas, grandes ou pequenas, falsas ou verdadeiras. $\mathrm{O}$ nosso pensamento não se acomoda às cousas, acomoda-se ao nosso gosto. ${ }^{37}$

Entretanto, uma vez que um dos pilares da argumentação de Matias Aires é o equilíbrio, e que mesmo os vícios podem engendrar virtudes, podemos questionar qual a virtude da escrita da história ou, ao menos, qual a virtude engendrada pela escrita da história. Essa virtude pode ser

${ }^{34}$ KOSELLECK, 1993.

35 KOSELLECK, Citado por COSTA LIMA, 2006.

${ }^{36}$ GUMBRECHT, 1998.

${ }^{37}$ AIRES, 1942. 
encontrada no fato de a escrita da história criar a tradição, que é o modo como a sociedade se reconhece como um corpo distinto dos demais. Além disso, à medida que se valoriza cada vez mais essa tradição, a vaidade do homem individual trabalha para que seu reconhecimento se relacione ao reconhecimento da sua sociedade. Por isso os homens, individualmente, agem pela sociedade, ao menos no ponto de vista do discurso, pois a vaidade de ser reconhecido por um ato heróico supõe a vaidade da humildade ao reconhecer tal feito como individual.

Assim, a análise que Matias Aires pretende fazer do homem e da sociedade depende de uma análise dos fundamentos da sociedade. E um dos seus principais fundamentos é a desigualdade dos homens baseada na instituição da nobreza hereditária. O que legitima essa nobreza é a história profana, a transformação da história crua em história narrada através do discurso elaborado pelo homem. As críticas feitas a essa história são da seguinte ordem: ela não tem valor porque não é verdadeira e, ela legitima de maneira falsa uma instituição decadente, que tentou colocar a legitimação da sua superioridade em fatos naturais, desconsiderando, pois, a igualdade da Criação dos seres humanos. A fim de assegurar essa desigualdade, a nobreza transfere sua legitimação para o sangue, que seria transmissível. Sendo fundamentada no elemento natural (biológico), a vaidade de origem não exige que os homens sejam reconhecidos por suas ações, inibindo aquilo que potencialmente a vaidade gera de virtuoso: coesão social promovida pelo desejo de reconhecimento. Corrompido o desejo de reconhecimento social, e restando da vaidade apenas o desejo de diferenciação individual, a vaidade pode desagregar a comunidade.

Como não existe maneira de legitimar a hierarquização social por meio unicamente do fato biológico (Matias Aires argumenta que o sangue é igual entre todos os animais da Criação), a história é a responsável por trazer uma fundamentação extra-natural para a nobreza. Entretanto, a história também se apóia no humano - e aí reside seu erro: as hierarquias devem ser estabelecidas, senão somente por atos, por contato com uma força transcendente: mitos, deuses, dentre outros, mas não no exclusivamente humano. Ao deslocar a legitimação da hierarquia para algo transcendente, essa legitimação se torna mais verdadeira: 
(...) o Autor do mundo fêz ao homem sôbre uma mesma idéia uniforme, e igual, e na ordem com que dispôs a natureza, não conheceu exceções, nem privilégios: nunca o homem pode ser mais, nem menos, que homem; e por mais, que a vaidade lhe esteja sugerindo uns certos atributos, ou certas qualidades, que o fazem parecer maior, e mais considerável, que os mais homens, essas mesmas qualidades, ainda sendo verdadeiras, sempre são imaginárias; porque também há verdades fantásticas e compostas sòmente de ilusōes. ${ }^{38}$

Matias Aires não tem por objetivo elaborar uma teoria do que seja a história, entretanto, a elege como algo fundamental e estruturante para seu argumento, uma vez que a tradição reencenada e continuamente representada pela história se configura como a maneira específica como aquela sociedade se torna uma segunda natureza. A análise dos conceitos de História e de escrita da história, elaborados e utilizados pelo autor, por conseguinte, se torna imprescindível para a compreensão do sentido geral da obra de Matias Aires, assim como inclui este autor no debate que estava sendo travado, no século XVIII, acerca do sentido da história humana e das maneiras como essa história deveria ser entendida e narrada.

\section{Referências bibliográficas}

AIRES, Matias. Reflexóes Sobre a Vaidade dos Homens ou Discursos Moraes Sobre os Effeitos da Vaidade offerecidos a El-Rei Nosso Senhor D. Josepho I. São Paulo: Livraria Martins, 1942. 1. ed: 1752. (1761, 1778, 1786).

AIRES, Matias. Carta Sobre a Fortuna. In: AIRES, Matias. Reflexóes Sobre a Vaidade dos Homens e Carta Sobre a Fortuna. Lisboa; Imprensa Nacional Casa da Moeda, 1980.

AMOROSO LIMA, Alceu (Thristão de Atayde). Introdução. In: Reflexões Sobre a vaidade dos homens ou Discursos moraes sobre os effeitos da vaidade offerecidos a El-Rei Nosso Senhor D. Josepho I. São Paulo: Livraria Martins, 1942.

${ }^{38}$ AIRES, 1942. 
ARAUJO, Valdei Lopes de. Para além da auto-consciência moderna: a historiografia de Hans Ulrich Gumbrecht. Varia História, Belo Horizonte, v. 22, p. 314-328, jul/dez 2006.

CÉSAR, Constança Marcondes. As 'Reflexões' de Matias Aires. Revista Brasileira de Filosofia, v. XIX, fascículo 73, janeiro-março, 1969.

COELHO, Jacinto do Prado. O vocabulário e a frase de Matias Aires In: Boletim de Filologia. Lisboa: Centro de Estudos Filológicos, 1954/1955. Tomo XV.

COELHO, Jacinto do Prado. Reflexões sobre as reflexões. In: AIRES, Matias. Reflexões sobre a vaidade dos homens e Carta sobre a fortuna. Lisboa: Imprensa Nacional - Casa da Moeda, 1980.

COELHO, Jacinto do Prado. O Humanismo de Matias Aires: Entre o Cepticismo e a Confiança. Revista Brasileira de Filosofia, n. 57, janeiro-março, 1965.

COSTA LIMA, Luis. O Redemunho do Horror: as margens do ocidente. São Paulo; Editora Planeta do Brasil, 2003.

COSTA LIMA, Luis. História, ficção, literatura. São Paulo: Companhia das Letras, 2006.

CUNHA, Norberto Ferreira da. A física do corpo humano em Luís Antônio Verney. In: CUNHA, N. F. Elites e acadêmicos na cultura portuguesa setecentista. Lisboa: Imprensa Nacional - Casa da Moeda, 2001. p. 219 a 246.

ENNES, Ernesto. Dois paulistas insignes: José Ramos da Silva e Matias Aires Ramos da Silva e Eça. São Paulo: Companhia Editora Nacional, 1944.

GUMBRECHT, Hans Ulrich. As funções da retórica na Revolução Francesa - estudos preliminares para uma pragmática histórica do texto. Belo Horizonte: Ed. UFMG, 2003.

GUMBRECHT, Hans Ulrich. História e redenção. Rio de Janeiro: Fundação Casa de Rui Barbosa, 2000.

GUMBRECHT, Hans Ulrich. Modernização dos sentidos. São Paulo: Editora 34, 1998. 
HADDAD, Jamil Almansur. Matias Aires, Filósofo Barroco do Brasil In: Revista Brasileira de Filosofia. v. IX, fascículo I, janeiro - fevereiro - março 1959.

HANSEN, João Adolfo. Ler e ver: pressupostos da representação colonial. Disponível em: <http://www.geocities.com/ail_br/lerverpressupostos.htm>. Acesso em: 29 out. 2007.

HANSEN, João Adolfo. Barroco, neobarroco e outras ruínas. FLOEMA Caderno de Teoria e História Literária. Ano II, n. 2 A, outubro 2006. Vitória da Conquista; Edições UESB, 2006. (Especial João Adolfo Hansen).

HAZARD, Paul. O pensamento europeu no Século XVIII - de Montesquieu a Lessing. Lisboa: Editorial Presença, 1989.

KOSELECK, Reinhart. Futuro pasado: para una semantica de los tiempos historicos. Barcelona: Ed. Paidos, 1993.

MESQUITA, Antônio Pedro. Homem, sociedade e comunidade politica: o pensamento filosófico de Matias Aires. Lisboa: Imprensa Nacional/Casa da Moeda, 2007.

MORSE, Richard M. O espelho de Prospero: cultura e idéias nas Américas. São Paulo: Cia. das Letras, 1995.

PÉCORA, Alcir. Máquina de gêneros: novamente descoberta e aplicada a Castiglione, Della Casa, Nóbrega, Camões, Vieira, La Rochefoucaud, Gonzaga, Silva Alvarenga e Bocage. São Paulo: EDUSP, 2001.

PINTO, Paulo Roberto Margutti. Reflexões sobre a vaidade dos homens: Hume e Matias Aires. Kriterion, v. XLIV, n. 108, p. 253-278, julhodezembro 2003.

VALINHAS, Mannuella Luz de Oliveira. Corpo e persuasão no Século XVIII: uma análise da idéia de corpo no Compêndio Narrativo do Peregrino da América (1728), de Nuno Marques Pereira e nas Reflexões Sobre a Vaidade dos Homens (1752), de Matias Aires. 2005. Dissertação (Mestrado) FAFICH/UFMG, Belo Horizonte, 2005. 


\section{Resumo}

Análise da obra "Reflexões sobre a vaidade dos homens ou Discursos morais sobre os efeitos da vaidade oferecidos a El-Rei Nosso Senhor D. José I", de Matias Aires.

\section{Résumé}

Analyse de l'oeuvre "Reflexôes sobre a vaidade dos homens ou Discursos morais sobre os efeitos da vaidade oferecidos a El-Rei Nosso Senhor D. José I", de Matias Aires. 